\title{
THE MULTI-TECH PROTECTIVE MONITORING OF THE LION FOREST GARDEN STONY ARTIFICIAL HILLS (SUZHOU, CHINA)
}

\author{
F. Fu ${ }^{1, *}$, J. Zhang ${ }^{2}$, F. Shen ${ }^{2}$, C. Zhao ${ }^{3}$ \\ ${ }^{1}$ Beijing University of Civil Engineering and Architecture, Beijing, China - fufan@bucea.edu.cn \\ ${ }^{2}$ The Lion Forest Garden Administration, Suzhou, China - (89662649, 411505028)@qq.com \\ ${ }^{3}$ Huaqiao University, Xiamen, China - joy_cj@126.com
}

Comission II - WG II/8

KEY WORDS: Stony Artificial Hills, The Lion Forest Garden, Monitoring, World Heritage, 3D Scan, Side-Scan Sonar

\begin{abstract}
:
The Lion Forest Garden was originally built in 1342, during Yuan Dynasty, and became one of the most famous gardens in Suzhou. In 2000, it was inscribed in the World Heritage List as an extensive property of the Classical Gardens of Suzhou. The Lion Forest Garden is famous for its stony artificial hills covering more than 4,000 square meters, which were continually built during Yuan, Ming, and Qing Dynasty. However, as a long time passed, stony artificial hills appear damaged showing stone cracking - which could be seen in many places-, gaping, weathering, water erosion, and subsidence. Besides, a new underground line will pass through the road west to the Garden. In 2018 and 2019, the Landscape Architecture Engineering Lab of the Beijing University of Civil Engineering and Architecture collaborated with the Lion Forest Garden Administration on a research to define the strategy to monitor these stony artificial hills. Multiple technologies were used, such as 3D Scanning, Ultrasonic Testing, Side-Scan Sonar, sensors, and so forth. During the monitoring, some technologies worked well while others did not. The paper, based on the mentioned research, will discuss the strategy and technologies used in monitoring historical rockeries, describe the procedure, analyse the outcomes, and find out the reasons causing the unsuccess of some technologies.
\end{abstract}

\section{INTRODUCTION}

\subsection{The Artificial Hills in Chinese Garden}

The artificial hills have a very important position in Chinese garden, especially in the impressionistic landscape garden. In the past, 'hill master' and 'hill craftsman' were usually used to describe the garden designer, showing the importance of artificial hills in Chinese Garden.

The artificial hills first appeared in Han Dynasty, and the art of hill-making had reached maturity in Song Dynasty with the masterpiece of the artificial hills in Genyue Royal Garden. Since then, they have continued to develop, especially the stony artificial hills, which have become more and more complicated in structure. The structure of stony artificial hills developed from a beam-wall structure to a cantilevered beam one, and to an arched structure invented by Ge Yuliang, a gardener from the middle Qing Dynasty. Besides, the shape of the artificial hills has learnt more and more from landscape painting and painting theory.

\subsection{The Artificial Hills in the Lion Forest Garden}

The Lion Forest Garden (Figure 1), in Suzhou, was built in the late Yuan Dynasty (1342 A.D.) by a fellow of a Zen master, Tian $R u$ Wei Ze, an eminent monk of the Yuan Dynasty. It is named after the lion-like stones of the artificial hills in the garden. Then, the Lion Forest converted from the original temple to a garden owned along time by many families. The Lion Forest Garden is one of the high reputation "Four Famous Gardens" in Suzhou. Emperor Qianlong of Qing Dynasty visited the Lion Forest many times, and he extremely loved it so that he built another garden on the basis of the Lion Forest and then built a third copy of it in the Imperial Mountain Summer Resort.

In 2000, the Lion Forest Garden and other four classical gardens in Suzhou were approved to be inscribed in the World Cultural Heritage List.

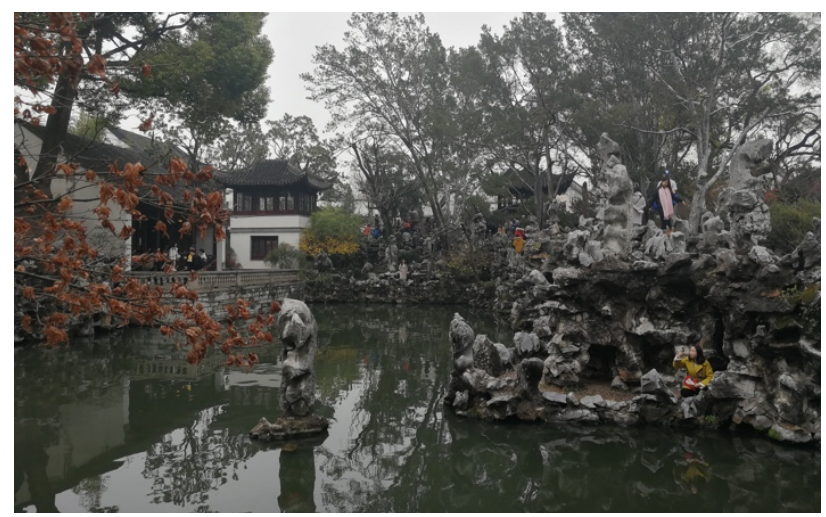

Figure 1. The Lion Forest Garden

The Lion Forest Garden is famous for its stony artificial hills, which are the main part of the garden, covering an area of more than 4,000 square meters. Major part of the artificial hills in the Lion Forest Garden are made of 'Taihu' (literally, Big Lake) stone, a kind of limestone, some others are of Huang (literally, Yellow) stone, a kind of yellow metamorphic rock, and the western artificial hill is made of earth with stone decoration. The artificial hills simulate the real mountain, having peaks, valleys, gaps and caverns. The main hills have nine routes, along which visitors can appreciate the attractions, buildings,

* Corresponding author 
bridges, caverns and surrounding views. The routes are so winding and complex that the visitors often get lost in the artificial hills. The artificial hills are of long history, large scales, complex spatial arrangement, exquisite art and superb skill. Thus, the Lion Forest Garden is unique in China and is called "the kingdom of artificial hills". About 3 millions of tourists visit this garden every year.

\subsection{The Damage Issues of the Artificial Hills in the Lion Forest Garden}

The stony artificial hills of the Lion Forest Garden are now facing the problem of damage (Figure 2). The main causes of damage are: 1) the artificial hills are extremely heavy and their structure cannot sustain the increasing live loads caused by the large number of tourists, resulting in cracks, falling off and collapse; 2) the foundation bearing capacity of the artificial hills changes with time passing, resulting in uneven settlement, and in the damage of the artificial hills; 3 ) the roots of the trees present on the hills continue to erode and push the stones as time passes, and their growing crowns increase the wind load, aggravating the damage caused by roots; 4) the erosion of rainwater, especially acid rain, leads to the erosion of the gap between stones and the stone surfaces; 5) tourists stand and lean against the rocks, resulting in the fracture of the rock peak; 6) the long-term immersion in the water body causes the loosening of rocks, resulting in the collapse. In recent years, there have been many events of damage in the garden, including the falling down of stones, stones broken and the collapse of revetment. Most of these damage events suddenly happened without any obvious sign before. Once the problem appears, it will affect the authenticity of artificial hills, hurt the tourists and cause economic loss to the garden.
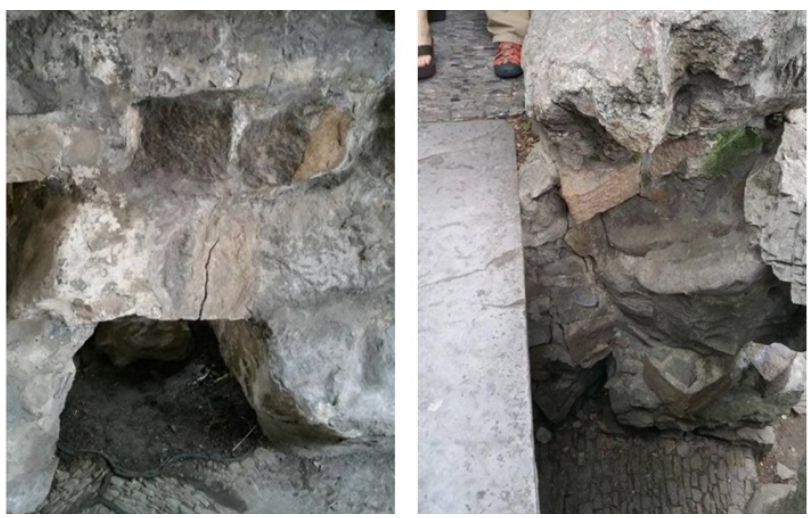

Figure 2. The cracks on the stones of the artificial hills

Because of the lack of effective non-destructive testing methods for the damages of artificial hills, the check of their state is usually carried out by rockery craftsmen. They judge the damage levels by their experience, so it causes a great uncertainty that influences the efficiency of the protection of artificial hills. When the damage of artificial hills aggravates, they will be closed to protect them, and the potential inconvenience for the tourists must be calculated, such as it happens for the artificial hills in the Forbidden City and the 'Jinxing' (literally, Peaceful Mind) Garden of Beihai (literally, North Sea) Park, Beijing, the artificial hill in the 'Huanxiu' (literally, Surrounded by Attractions) Villa, Suzhou, and the one of 'Huang' stone in the 'Yu' (literally, Delighting Parents) Garden, Shanghai. This kind of protection is not ideal, because it can only partially alleviate the aggravation of the damages, but it cannot completely solve the problem, such as the cracks caused by uneven settlement, the cracks caused by rainwater and tree roots, which will continue to deteriorate after closure. In addition, artificial hills are the most essential part of garden. After closure, it is impossible to appreciate its artistic value. For example, the artificial hills in the Lion Forest Garden are the main attraction of the garden, and the most fun of the tourists is taken from going through the hills along the routes, and enjoy the surrounding scenery in different positions.

Therefore, the artificial hills in the Lion Forest Garden urgently need to investigate their damage situation, detecting the damage degree, monitoring the damage procedure, analysing the outcomes, and proposing the corresponding protection strategies.

\section{LITERARY REVIEW OF THE ARTIFICIAL HILLS}

\subsection{Studies on the History and Art of Artificial Hills}

There are many studies on artificial hills in Chinese Garden, mainly focusing on the history and artistry of artificial hills, including overall introduction to the artificial hills in Chinese Garden (Zhang, 1994; Cao, 2009; Wei, 2009; Li, Wei, 2009; Meng, 2011b; Gu, 2017), introduction to the historical development of artificial hills (Cao, 1980; Li, 2000; Wang, 2007), artistic characteristics of artificial hills during a certain period (Zhang, 1996; Bao, 2012), artistic characteristics of artificial hills in a certain garden type or a certain local style, such as artificial hills in royal gardens (Wang, 2009; Xie, 2013), artificial hills in private gardens (Jia, 2007; Wang, 2008), artificial hills in Suzhou gardens (Sun, 1998; Bu, 2013), and artificial hills in Southern China gardens (Liang, 2014). There are many case studies of artificial hills, such as the artificial hills in the inner garden of Forbidden City (Zheng, 2005), in Beihai Park (Meng, 2011a), in Fragrant Hills (Sun, 2013), in Old Summer Palace (Jia, 2016), and in other royal gardens (Dong, 2007), and the artificial hills in the Huanxiu Villa and other private gardens (Zheng, 2015). Some specific forms of artificial hills were researched, such as the form of Fen Bi Li Shi (literally, rockery against wall) (Zhang, 2015), Shi Yun Ti (literally, rockery stairs) (Li, 2017), and Ting Ju Shan Dian (literally, pavilion on the top of the hill) $(\mathrm{Gu}, 2016$; Zhao, 2017). There is also studies on the image of artificial hills in literature (Zhu, Wang, 2016), as well as studies on the relationship between stone types and hill forms (Zhuang, 2002; Ouyang, Zhang, Fu, 2015; Li, Wei, 2017). The famous rockery craftsmen in history, such as $J i$ Cheng (Cao, 1982; Li, Fu, Li, 2012;), Zhang Nanyuan (Cao, 1988; Qin, 2017), Shi Tao (Xu, Li, 2014), Ge Yuliang (Cao, 2004), their works and styles were studied. Some studies focus on the inheritance and development of artificial hills nowadays (Liu, 2006; Han, 2009; Lou, 2011).

\subsection{Studies on the Crafts of Artificial Hills}

There are a few documents on the crafts of artificial hills, mainly including the records of artificial hill designers and craftsmen (Wang, 1979; Meng, 1991a, 1991b; Bu, 2005), the summary of artificial hill crafts by rockery craftsmen (Zheng, Fang, 1999; Fang, 2005; Han, 2010), and the relevant chapters in the garden engineering textbooks (Meng, 2012). Generally, the research on this field is insufficient, especially the research on structural mechanics of hills and structural performance of stones, therefore, the current construction of artificial hills is completely dependent on the experience of craftsmen instead of the structural calculation. 


\subsection{New Technologies Used in Studies on Artificial Hills}

With the development of digital technology, new technologies and methods began to be applied to the research and practice of artificial hills, such as using space syntax to analyse the spatial complexity of artificial hills (Yang, 2016; Li, Yang, Gu, 2017; Yang, Zhang, 2018;), digital modelling to optimize stone stacking of artificial hills (Bai, 2015), and surveying artificial hills by 3D laser scanning and 3D image generation technology (Bai, 2015; Gu, Gu, Yang, 2016). The 3D digital technologies solve the problem that the traditional surveying methods can't precisely survey artificial hills and display on 2D drawings (Wang, Hu, 2018).

The researches on the damage detection of artificial hills is few. Although the non-destructive detection of stone relics has been applied for many years, including ultrasonic (Zhang, Peng, Ma, Bai, Ma, 2005; Ma, Zheng, Yan, Xiang, Wang, 2015), Rayleigh wave (Yuan, 2006), infrared thermal imaging (Zhang, 2013), close range photogrammetry $(\mathrm{Li}, 2012)$ and other methods (Zhu, 2013), it has not been applied to the damage detection of artificial hills due to their complicated shapes.

\section{THE ATTEMPT ON MULTI-TECH PROTECTIVE MONITORING ON THE ARTIFICIAL HILLS}

\subsection{Time and Place}

In 2018 and 2019, the Lion Forest Garden Administration and the Landscape Architecture Engineering Laboratory of the Beijing University of Civil Engineering and Architecture collaborated to work on the monitoring technologies for damage detection of the artificial hills in the Lion Forest Garden. At first, two places have been selected to start the monitoring: 1) the artificial hill in the south of the 'Woyun' (literally, Sleeping on Cloud) Chamber (Figure 3), which are vestiges of Yuan Dynasty and are plenty of cracks on the stones, so it is necessary to check the damage situation; 2) the artificial hill in the pond (Figure 4), which reaches the highest aesthetic value among the artificial hills, and in recent years, the ground near the stone revetment partially subsided and water accumulation appeared, so it is necessary to detect the stone revetment.

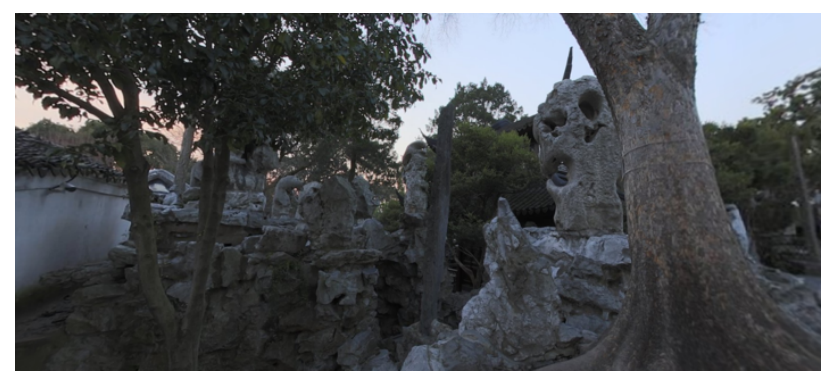

Figure 3. The artificial hill in the south of the Woyun Chamber.

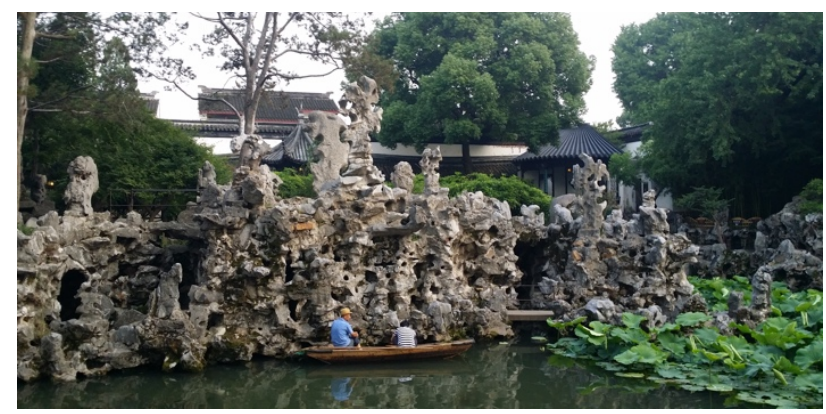

Figure 4. The artificial hill in the pond.
More, in 2019, a new underground line was proposed along the road in the west side of the Lion Forest Garden and its construction started in late 2019. The underground line is only 60 meters away from the west wall of the garden. The vibrations during construction and then into operation will affect the garden, including the artificial hills, especially the western hill (Figure 5).

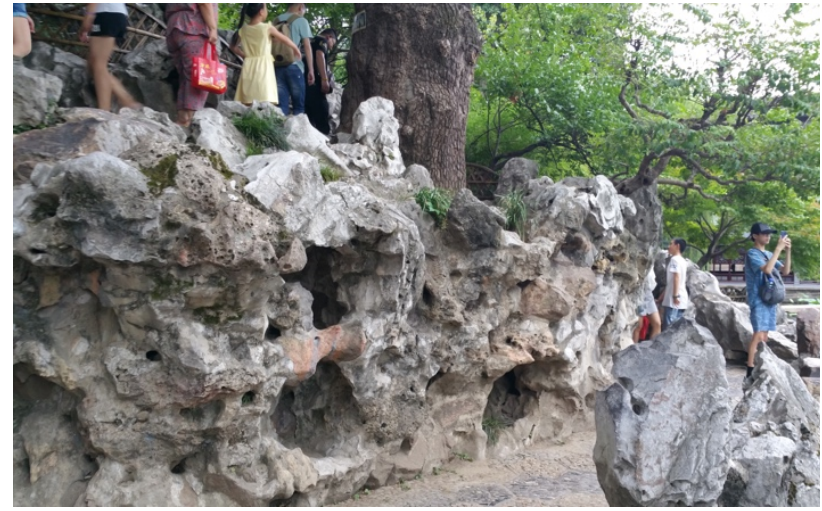

Figure 5. The western hill.

\subsection{Methodology}

The first step of the work on the artificial hill in the south of the 'Woyun' Chamber has been to 3D scan the artificial hill to gain the 3D data for reference (Figure 6). Due to the complicated shape of the artificial hill and the holes on the stones, large 3D scanner and portable 3D scanner have been needed. We have selected two large 3D laser scanners: Zhonghaida HS650 and Faro F330. The first can scan at a larger range, but it is bigger and heavier and the point-cloud data is relatively sparse, about 500,000 points per second (PPS); the second is smaller and lighter, easier to operate, and good in point-cloud data, 960,000 PPS, but its scanning range is smaller. The used portable scanner is the Creaform H700 3D laser scanner, used to scan the caves and holes on the stones.

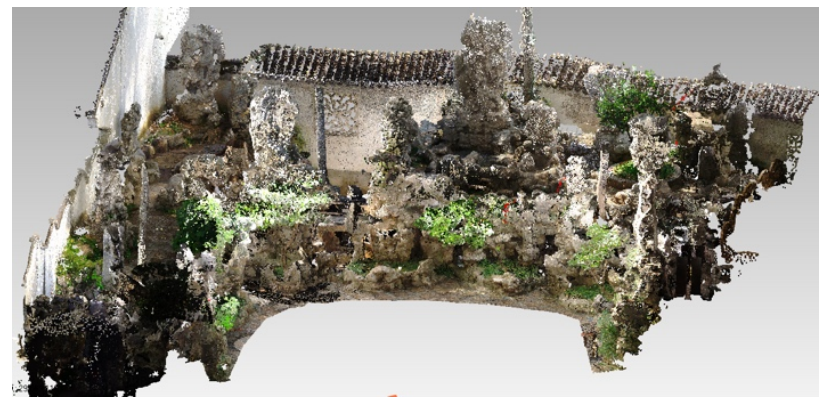

Figure 6 . The 3D point cloud model

The second step was to measure the cracks on the artificial hill. The hill was divided into five areas, each crack was numbered, and the data about length, width, and depth were collected. In the beginning, it was planned to use ultrasonic testing to get the data, but it didn't work well because the stone surface is uneven and there are many cracks in the same stone, so that it is impossible to use the ultrasonic crack detector. Finally, thin probing rulers with graduations were used to measure the dimensional data.

The third step was to count and show the data in a convenient way. All the cracks' data were listed in an EXCEL file. Due to 
the complexity of the shape of the artificial hill, it was difficult to mark all the cracks on 2D drawings. To mark all cracks with dimensional data on 3D model was also difficult because the model was too big. Thus, panoramic photography was used to show data. All the cracks were marked with labels on which the data were written down, and then photographed by a Matterport 3D camera (Figure 7).

The fourth step was the data analysis. Other work also included fine mapping of the model and display of the paths (Figure 8).

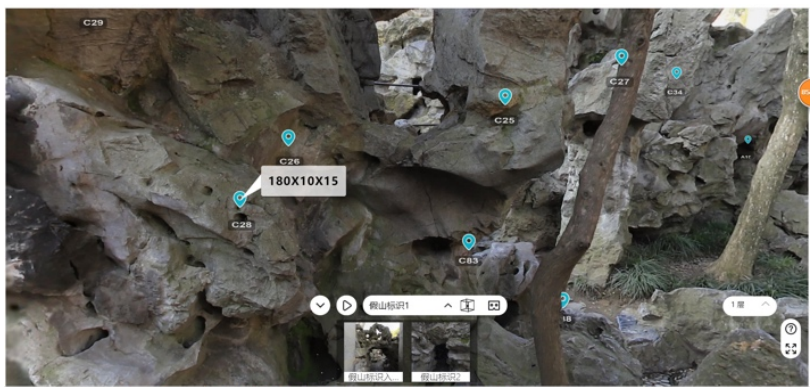

Figure 7. The panoramic photo to show data of cracks.

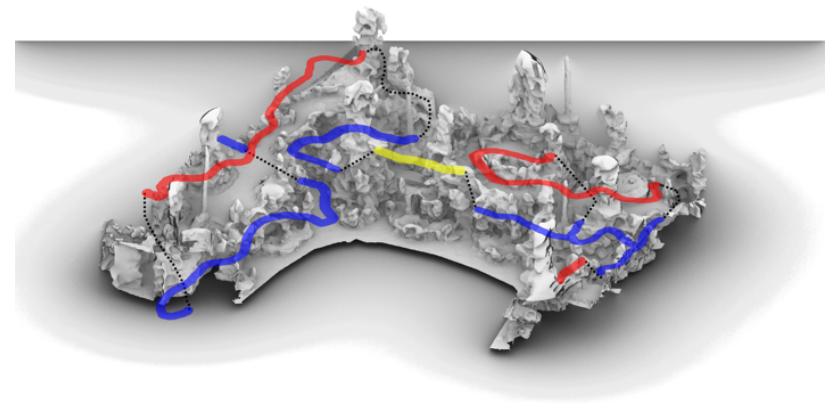

Figure 8 . The paths showing.

Work on the stone revetment of the artificial hill in the pond was relatively difficult, because the foundation of the artificial hill had been in the water for a long time and reached stability. If the water was pumped out, it would be easy to detect the revetment, but it would lead to changes in the mechanical forces on the revetment itself and onto the foundation of the artificial hill, provoking changes in the oxygen conditions of the foundation and influencing badly on the artificial hill structure. Therefore, the work must be carried out in the water, and it should have been necessary to find suitable waterproof instruments. Thus, all the cracks' locations and information can be clearly seen on the photo.

The first attempt was to do a 3D scan of the revetment to gain the 3D data for reference. However, after trying Robotics ULS-200 underwater 3D measurement, it was found that this way was impossible because the water in the Lion Forest Garden was of high turbidity. There were too many algae and suspended substances in the water, so the laser beam was blocked by the particles in the water and could not be effectively projected to the revetment, and unable to form a complete 3D model.

Due to the absence of suitable three-dimensional scanning equipment, image technologies were tried, including side scan sonar and endoscopy. After scanning the revetment by Iside 1400 side sonar scan, the course surface image was formed, and the shape of revetment could basically be recognized (Figure 9). And then a viZaar INVIZ SNK 40X endoscope was used to take

pictures of the revetment (Figure 10). Because the stone revetment was covered by algae and moss, the cracks were not visible.

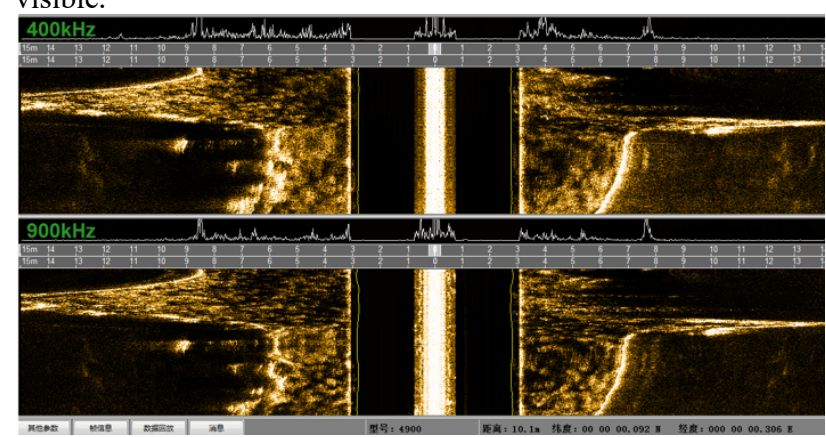

Figure 9 . The images of the revetment by side sonar scan.
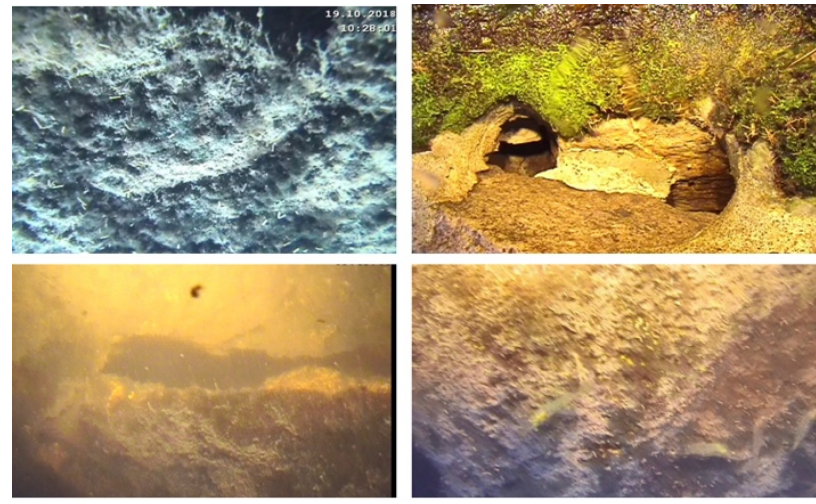

Figure 10. The images of the revetment by endoscope.

The work on the western hill included 3D scanning and installation of sensors. The hypothesis was that the vibration produced by the construction and operation of new underground line would damage the western hill. Thus, the western hill and buildings on it were 3D scanned to get 3D model for reference, and 5 kinds of sensors, thermal, humidity, deflection, vibration, and tilt were installed in different positions to monitor the vibration and its causes. The data will be used to compare those during upcoming construction and operation in the future.

\section{DATA ANALYSIS AND DISCUSSION}

There were found 793 cracks totally. From a single dimension, the crack length range was from 20 to $1,500 \mathrm{~mm}$, mainly between 100 and $300 \mathrm{~mm}$, accounting for $64.4 \%$ of the total (Figure 11); the crack width range was from 1 to $100 \mathrm{~mm}$, mainly between 1 and $6 \mathrm{~mm}$, accounting for $66.3 \%$ of the total (Figure 12); the crack width range was from 1 to $500 \mathrm{~mm}$, mainly between 1 and $20 \mathrm{~mm}$, accounting for $85.8 \%$ of the total (Figure 13).

\section{LENGTH ( NUMBER)}

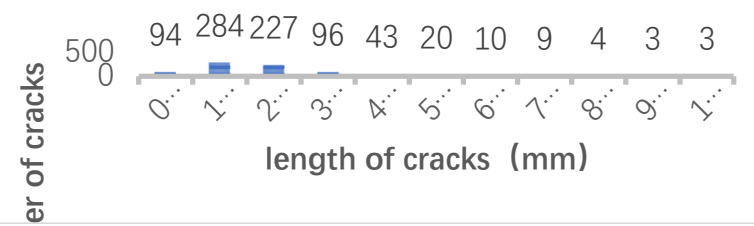

Figure 11. The number of the cracks' length. 


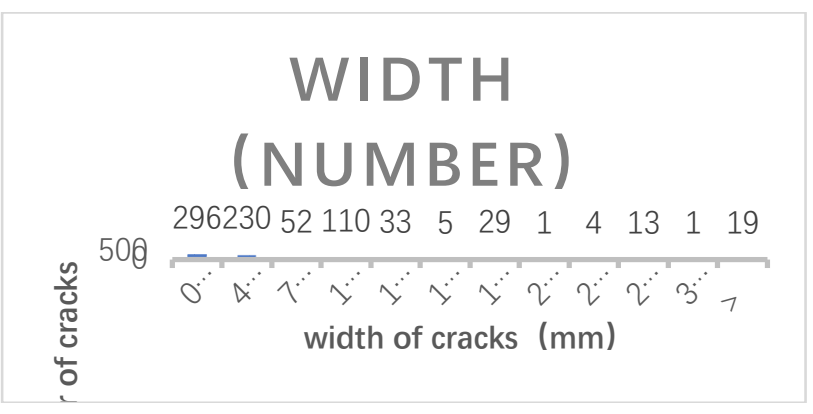

Figure 12. The number of the cracks' width.

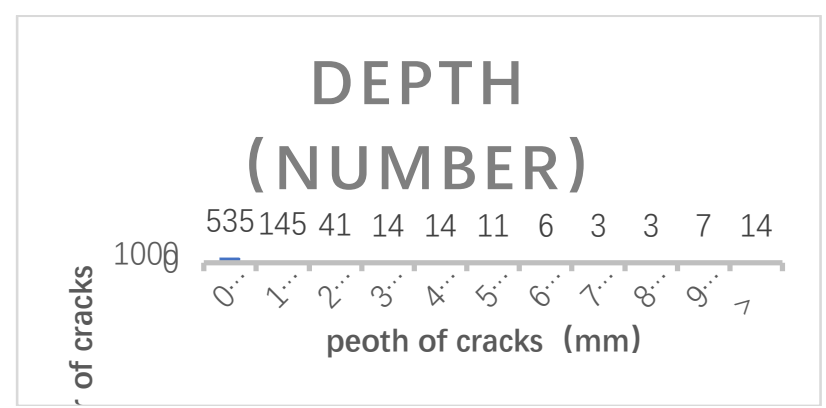

Figure 13. The number of the cracks' depth.

From the multi-dimensions, the number of cracks with length, width and depth greater than 100,3 and $10 \mathrm{~mm}$ sequentially is 300 , accounting for $37.8 \%$ of the total 793 cracks; the number of cracks with length, width and depth greater than 200,10 and 20 $\mathrm{mm}$ sequentially is 78 , accounting for $9.8 \%$ of the total; the number of cracks with length and width greater than 500 and 10 $\mathrm{mm}$ sequentially is 26 , accounting for $3.3 \%$ of the total. In addition, there are 23 cracks whose length and depth are greater than 500 and $20 \mathrm{~mm}$ sequentially, accounting for $2.9 \%$ of the total 793 cracks; 47 cracks whose width and length are greater than 20 and $200 \mathrm{~mm}$ sequentially, accounting for $5.9 \%$ of the total.

The number of cracks with depth and length greater than 50 and $200 \mathrm{~mm}$ sequentially is 41 , accounting for $5.2 \%$ of the total 793 cracks; the number of cracks with depth and width greater than 50 and $10 \mathrm{~mm}$ sequentially is 43 , accounting for $5.4 \%$ of the total; in addition, the number of cracks with length of greater than $1000 \mathrm{~mm}$ is 5 , accounting for $0.6 \%$ of the total.

The cracks with length, width and depth greater than 100, 3 and $10 \mathrm{~mm}$ sequentially can be easily identified by naked eyes at short distance, with the number reaching $37.8 \%$ of the total; the cracks with length, width and depth of greater than 200,10 and $20 \mathrm{~mm}$ sequentially can be obviously identified by naked eyes at short distance, with the number reaching $9.8 \%$ of the total. It shows that a large number of cracks in the artificial hill can be seen by tourists, and a large proportion of them may bring psychological insecurity to tourists. Therefore, the length, width and depth can be greater than 200, 10 and $20 \mathrm{~mm}$ at the same time.

Based on the analysis of the scatter diagram, three kinds of protection measures can be taken for cracks with different values: from top to bottom, the cracks in the first section can be observed and repaired if necessary; the cracks in the second section can be detected regularly to determine their development trend; the cracks in the third section can be observed regularly without treatment temporarily, and the retention period is taken as the mountain texture features.

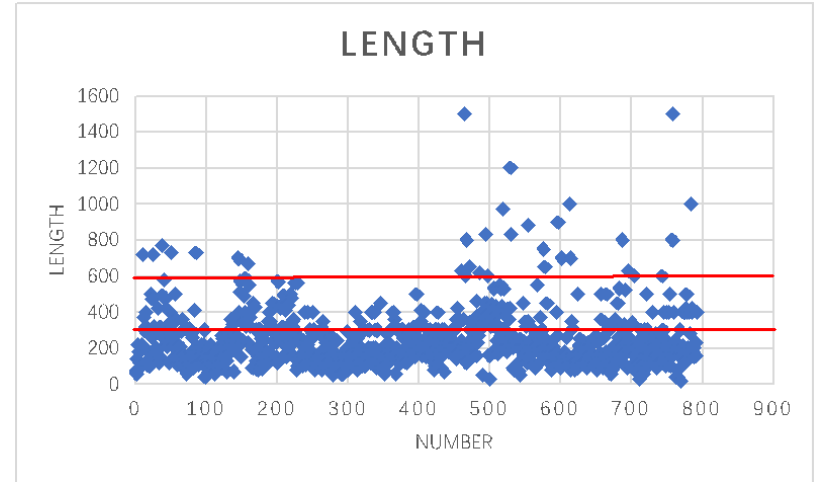

Figure 14. The three section of the cracks' length.

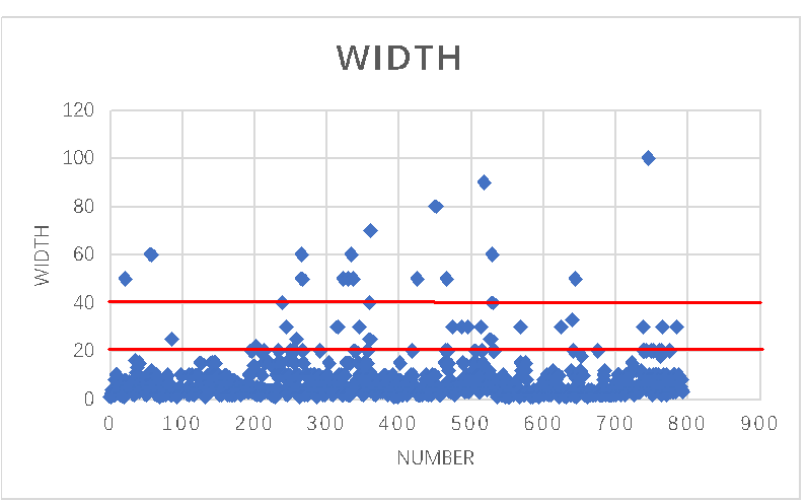

Figure 15. The three section of the cracks' width.

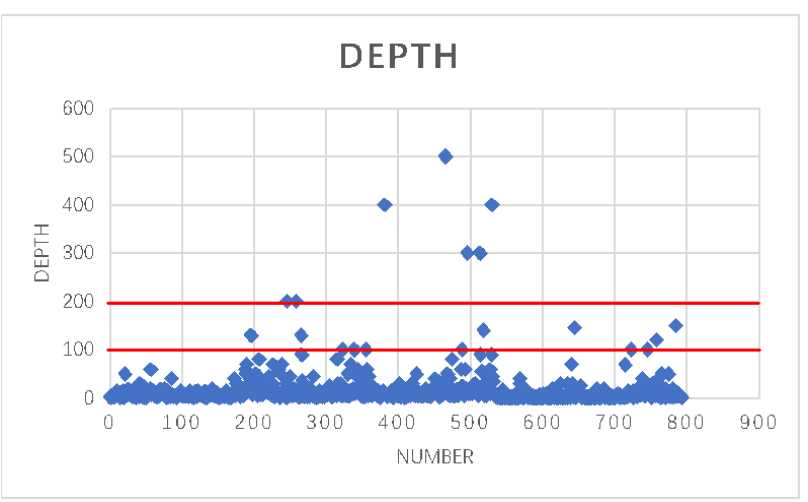

Figure 16. The three section of the cracks' depth.

The results of the work on the artificial hill in the south of the 'Woyun' Chamber are as expected, and nearly all the monitoring technologies used can basically meet the requirements. Only ultrasonic testing cannot be implemented, but it is expected that more advanced instruments can be used in the future.

The results of the work on the artificial hill in the pond are not as expected, due to the lack of waterproof detection equipment, it has been impossible to do the work in water currently. It is expected that more advanced instruments and technologies can be used in the future.

The results of the work on the western hill are expected when the construction of underground line starts close to the garden. The new data can be compared with the data collected for reference (Table 1). 


\begin{tabular}{|c|c|c|c|c|}
\hline & $\begin{array}{l}\text { Sensor } \\
\text { N.O. }\end{array}$ & Max & Min & Avg \\
\hline \multirow{3}{*}{$\begin{array}{c}\text { Temperature } \\
\left({ }^{\circ} \mathrm{C}\right)\end{array}$} & $1-1-\mathrm{T}$ & 35.40 & 27.22 & 31.31 \\
\hline & $2-1-\mathrm{T}$ & 33.98 & 27.11 & 30.545 \\
\hline & $3-1-\mathrm{T}$ & 29.31 & 29.09 & 29.20 \\
\hline \multirow{3}{*}{$\begin{array}{c}\text { Relative } \\
\text { Humidity } \\
\qquad(\%)\end{array}$} & $1-1-\mathrm{H}$ & 83.67 & 48.11 & 65.89 \\
\hline & $2-1-\mathrm{H}$ & 86.94 & 51.08 & 69.01 \\
\hline & 3-1-H & 53.05 & 47.83 & 50.44 \\
\hline \multirow{7}{*}{$\begin{array}{l}\text { Tilt Angle } \\
\left({ }^{\circ}\right)\end{array}$} & $1-1-Q$ & 0.21 & -0.22 & -0.005 \\
\hline & 1-2-Q & 0.14 & -0.18 & -0.02 \\
\hline & $2-1-Q$ & 0.08 & -0.20 & -0.06 \\
\hline & $3-1-Q$ & 0.05 & -0.21 & -0.08 \\
\hline & $3-2-Q$ & 0.34 & -0.03 & 0.155 \\
\hline & $3-3-Q$ & 0.24 & -0.09 & 0.075 \\
\hline & 3-4-Q & 0.18 & -0.12 & 0.03 \\
\hline \multirow{4}{*}{$\begin{array}{l}\text { Deflection } \\
\quad(\mathrm{mm})\end{array}$} & $1-1-\mathrm{N}$ & 1.166 & -2.852 & -0.843 \\
\hline & $1-2-\mathrm{N}$ & 1.254 & -3.191 & -0.969 \\
\hline & $2-1-\mathrm{N}$ & 1.254 & -3.191 & -0.969 \\
\hline & $2-2-\mathrm{N}$ & 5.946 & 2.482 & 4.214 \\
\hline \multirow{3}{*}{$\begin{array}{l}\text { Vibration } \\
(\mathrm{Hz})\end{array}$} & $1-1-Z$ & 18.457 & 17.001 & 17,729 \\
\hline & $2-1-Z$ & 16.992 & 16.015 & 16.504 \\
\hline & $3-1-Z$ & 14.453 & 13.500 & 13.977 \\
\hline
\end{tabular}

Table 1. Data gained in August for reference.

\section{CONCLUSION}

Because the damages of artificial hill are various and cannot be monitored by a single technology or equipment, multi-tech monitoring is the practicable methodology. 3D scanning, panoramic photography, sensor-scan, and other possible technologies, all these can be integrated into a comprehensive methodology. The efficiency, precision and post-processing complexity of various equipment are very different in use. Sometimes, traditional method is still useful, for example in measuring using the probing ruler. From the outcomes, the nondestructive monitoring can provide digital 3D models, detection of damages and data analysis, with a periodic monitoring, data in different period can be compared to evaluate the state and behaviour of the damages. This will enhance the protection of artificial hills in Chinese garden.

For damaged parts of the artificial hills, besides the monitoring methods already used, more technologies can be attempted. For example, other kinds of sensors (as displacement sensor, settlement sensor, crack sensor, tilt sensor and so on) can be installed to monitor, periodically and continuously obtaining data, and then conducting data analysis. In addition, cameras can be installed, and through video recognition the number of tourists on the artificial hills can be counted, and their behaviours can be analysed, to evaluate the potential damages to the artificial hills.

On the basis of sufficient data analysis, the damage mechanism research can come to a conclusion, and then new protective schemes can be proposed, such as limitation of tourists, oneway tour, partial closure, and other protective management policy, reinforcement, replacement of broken stones and other maintenance schemes.

\section{ACKNOWLEDGEMENTS}

This paper is financed by the National Natural Science Foundation Project (31570699) and Beijing Social Science Foundation Project (16LSB004). The authors appreciate the help of Prof. Guo Mingyou of Suzhou University, Mr. Wang Lixiang of Beijing Tianfengruida Technology Co, Ltd., and Prof. Luca Maria Francesco Fabris of Politecnico di Milano.

\section{REFERENCES}

Bai, X. F., 2015: Research on digital hill-stacking. North China University of Technology.

Bao, Q. X., 2012: From best hill landscape around Hangzhou West Lake to rockery of gardening in Southern Song Dynasty: study on the landscape and culture heritage value of Lingyin Feilai-Hill. Chinese Landscape Architecture, 28(8), 89-92.

Bu, F. M., 2005: Garden rockery series: inlaid stone patching and pointing. Garden, (11), 16-17.

Bu, F. M., 2013: Analysis and appreciation of rockery in Suzhou gardens. Chinese Landscape Architecture, (2), 100-104.

Cao, X., 1980: A brief discussion on the development and evolution of the art of Chinese ancient landscape architecture and stacking mountains. Architectural History and Theory (First episode), 74-85.

Cao, X., 1982: Research on JI Cheng. The Architect, (12), 1-16.

Cao, X., 1988: Garden master ZHANG Nanyuan (1): commemorating the $400^{\text {th }}$ anniversary of ZHANG Nanyuan's birth. Chinese Landscape Architecture, (1), 21-26.

Cao, X., 2004: Research on the biography of GE Yuliang: the end of GE Yuliang and the art of rockery in ancient Chinese gardens (part I). The Architect, (4), 98-105.

Cao, X., 2009: On the Art of gardening and stacking mountains in Chinese landscape architecture. Design Research, (3), 15-18.

Dong, L. K., 2007: Try to discuss the structure and artistic conception of the rockery in Zhuozhou Qing imperial palace. Wen Wu Chun Qiu, (3), 55-56+63.

Fang, H., 2005: The theory and technique of the hill-stacking. Beijing: China architecture \&Building Press.

Gu, K., 2016: Rethinking on rockery-top pavilion in traditional Chinese gardens: function, culture and idea change. Chinese Landscape Architecture, (7), 78-83. 
Gu, K., 2017: Tentative discussion on study of principles and models of rockery making in traditional Chinese garden. Journal of Human Settlements in West China, 32(2), 27-31.

Gu, L. Y., Gu, X. R., YANG, W., 2016: The application of 3D digital technology in landscape surveying and mapping-taking rockery surveying and mapping as an example. Architectural Journal, (S1), 35-40.

Han, J. Z., 2009: Inheritance and development of Chinese gardens rockery: study on the rockery of Beijing Olympic Forest Park. Architecture Technology, (11), 64-68.

Han, L. S., 2010: Hill-stacking skill by Shanshihan. Beijing: China architecture \&Building Press.

Jia, J., 2007: Rockeries in the private gardens in Beijing. Chinese Landscape Architecture, 23(2), 71-73.

Jia, J., 2016: An analysis of piling hill and placing stone on Old Summer Palace. Architectural History, (1), 117-137.

Li, S. H., 2000: Discussion on appreciation method of Chinese landscape architecture and mountain stone and its formation and development process. Chinese Landscape Architecture, (1), 8084 .

Li, Z. M., 2012: Research and application of rock cave cracks non-destructive detection based on close range photogrammetry. China University of Geosciences, Beijing.

Li, Y. Y., 2017: To build a ladder like the cloud, as if building from the hill - analysis on the design method of stone ladder in Chinese classical garden. Traditional Garden Architecture Study, (1), 23-27.

Li, H., Fu, F., Li, C. Q., 2012: Three great gardeners in late Ming Dynasty: a study on the lifetime of JI Cheng, WEN Zhenheng and ZHANG Nanyuan. Landscape Architecture, (6), 99-100.

Li, Y. Y., Wei, F. Y., 2009: Shape selection based on artistic conception - an analysis on the essence of Chinese landscape architecture rockery design principles. Traditional Chinese Architecture and Gardens, (3), 23-26.

Li, Y. Y., Wei F. Y., 2017: "Look for the right stone" and "Find the content of the stone" - the relationship between the materials and design of Chinese ancient landscape rockery. Traditional Chinese Architecture and Gardens, (3), 39-42.

Li, Y. X., Yang, M., Gu, X. R., 2017: Landscape analysis of the mountain villa embracing beauty based on Space syntax. Chinese Horticulture abstracts, 33(1), 149-151.

Liang, M. J., 2014: An analysis of rockery-making in Southern China landscape architecture. Art Journal, (2), 82-87.

Liu, Y., 2006: The inheritance and development of rockery art in Beijing area. Beijing Forestry University.

Lou, J. Y., 2011: Analysis of the problems in the contemporary garden. Modern Horticulture, (13), 74-75.

Ma, H. L., Zhen, G., Yan, M., Xiang, J. K., Wang, C., 2015: Application of ultrasonic wave velocity analysis and first wave amplitude analysis method in fracture detection of stone relics. Wenbo, (6), 90-94.
Meng, Z. Z., 1991a: The seventh lecture: identifying stones, structure and waterscape in drop-mountain (Chapter I). Traditional Chinese Architecture and Gardens, (2), 51-55.

Meng, Z. Z., 1991b: The seventh lecture: identifying stones, structure and waterscape in drop-mountain (Chapter II). Traditional Chinese Architecture and Gardens, (3), 54-59.

Meng, Z. Z., 2011a: Superficial Analysis of Rockery in the North Sea. // Meng Z .Z. Theory and Practice of Landscape Architecture, Tianjin University Press, Tianjin, 35-39.

Meng, Z. Z., 2011b: Rockery, garden engineering, stone setting// Meng, Z. Z. Theory and Practice of Landscape Architecture. Tian Jin University Press, Tianjin, 40-44.

Meng, Z. Z., 2012: Landscape architecture engineering. China Forestry Publishing House, Beijing.

Ouyang, L. Q., Zhang, B., Fu, F., 2015: The differences in choosing stones among Yuan Ye, Superfluous Things and Xian Qing Ou Ji. Huazhong Architecture, (9), 155-158.

Qin, K., 2017: Glimpse of rockery and garden of ZHANG Clan: a case study on Yu Garden of QI Biaojia. Huazhong Architecture, 35(12), 18-22.

Sun, H., 1998: Peak stone and rockery in Suzhou garden. Traditional Chinese Architecture and Gardens, (1), 48-49.

Sun, J., 2013: Piling hill research about Jingyi garden on Fragrant Hills. North China University of Technology.

Wang, X. B., 1979: Rockery // Teaching and research group of architectural history, Department of architectural engineering, Tsinghua University. Collection of architectural history treatises (Volume III). Department of architectural engineering, Tsinghua University.

Wang, J. T., 2007: Study on stone piling evolution and its reasons in Chinese classical garden. Huazhong Architecture, 25(8), 188-190.

Wang, J. T., 2008: Relationship between stone piling and landscape painting in Ming-Qing gardens. Huazhong Architecture, 26(2), 170-172.

Wang, J. T., 2009: Study on rockery of Chinese imperial gardens. Tsinghua University.

Wang, S. W., Hu, J., 2018: The digital vision of Qianlong Garden. Beijing: China architecture \&Building Press.

Wei, F. Y., 2009: A study on Chinese landscape design theories of placing stone and piling hill. Beijing Forestry University.

Xie, S., 2013: Study on lake-rock rockworks in Beijing royal garden. North China University of Technology.

Xu, L., Li, J. Y., 2014: Yangzhou pieces of rock hill housing the unique copy in the world of Shi Tao's artificial rockwork and discussion with Mr. CAO Xun on historical facts about SHI Tao's building a landscape garden in Yangzhou. Chinese Landscape Architecture, (8), 116-119. 
Yang, Q. Y., 2016: The comparative study on the spatial characteristics of Chinese rockery and the winding path space of Europe maze garden based on Space syntax. South University.

Yang, Q. Y., Zhang, J. L., 2018: Analysis on the mystery of the main rockery in lion forest garden based on Space syntax. Chinese landscape architecture, (4), 129-133.

Yao, S. P., 1993: GE Yuliang - a rockery artist in the Qing Dynasty. Chinese Landscape Architecture, (02), 22.

Yu, M. Z., Lin, X., 2017: Study on the surveying methods based upon the 3D laser scanning and close-range photogrammetric techniques of the rockery and pond in the classical Chinese gardens. Landscape Architecture, (2), 117-122.

Yuan, J. B., 2006: Research on Rayleigh wave method and its application to inspection for weathering degrees of lithoid cultural relics. China University of Geosciences, Beijing.

Zhang, C. L., 1994: On the art of stacking mountains in Chinese landscape architecture. Traditional Chinese Architecture and Gardens, (4), 2-7.

Zhang, S. Q., 1996: Discussion on art of ancient Chinese acting stone from Japan. Chinese Landscape Architecture, (3), 45-47.

Zhang, H. H., 2013: The experimental study on the use of infrared thermal imaging for non-destructive detection of deterioration disease in stone relics. Journal of Liaoning Provincial College of Communications, (6), 20-22.

Zhang, B. Q., 2015: A research on the landscaping of stones in front of whitewashed wall in Chinese traditional garden and its application in modern garden. $\mathrm{Xi}$ ' an University of Architecture and Technology.

Zhang, Z. G., Peng, H., Ma, Y. S., Bai, J. Q., Ma, X. M., 2005: Application of the ultrasonic flawless detector in the preservation of unearthed stony cultural relics. Journal of Geomechanics, 11(3), 278-265.

Zhao, J. J., 2017: Landscape experience with mountain-top pavilions in Chinese traditional pavilion proses. Chinese Landscape Architecture, (9), 10-16.

Zheng, L. Z., 2005: The art of the rockery piling in the Ningshou palace garden. Palace Museum Journal, (5), 207-218.

Zheng, W. K., 2015: The fake of the rockery, the technique of piling hill in mood of a painting in rockery of Huanxiu Villa. New Arts, (8), 79-91.

Zheng, Q., Fang, H., 1999: Hill-stacking method. Nanjing: Jiangsu Fine Art Press.

Zhu, J. C., 2013: Application of geophysical prospecting methods in the protection of stone relics. Lanzhou University.

Zhu, L. N., Wang, Y. Y., 2016: There are gullies in the chest imagination of hill making and stone arrangement in "A dream of red mansions". Studies on "A Dream of Red Mansions", (5), 302-311.

Zhuang, S. Y., 2002: Discussion on selection and layout of rockery in garden and park. Chinese Landscape Architecture, 18 (1), 82-84. 